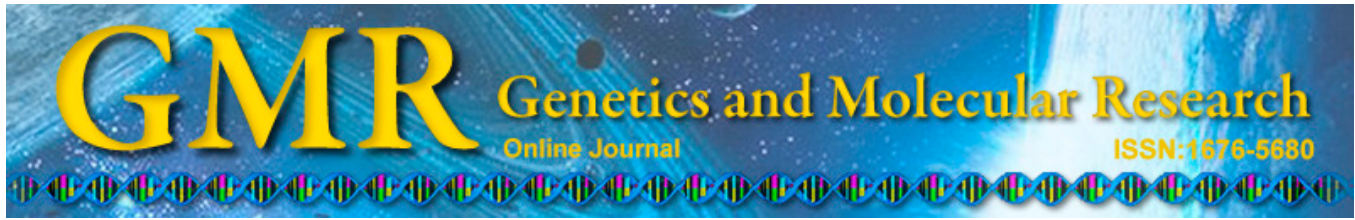

\title{
Additional chromosomal abnormalities in core-binding factor acute myeloid leukemia
}

\author{
H.H. Hsiao, ${ }^{1,2, *}$, Y.C. Liu ${ }^{1,2 *}$, H.C. Wang1, Y.F. Tsai ${ }^{1}$, C.H. Wu ${ }^{1}$, S.F. Cho ${ }^{1}$, \\ J.F. Hsu' ${ }^{1}$, C.T. Huang ${ }^{1}$, S.Y. Hsiao ${ }^{1}$, C.P. Lee ${ }^{1}$, C.S. Chang ${ }^{1,4}$, S.F. Lin ${ }^{1,4}$ \\ and T.C. Liu ${ }^{1,3,4}$ \\ ${ }^{1}$ Division of Hematology-Oncology, Department of Internal Medicine, \\ Kaohsiung, Taiwan \\ ${ }^{2}$ Department of Medical Research, Kaohsiung Medical University Hospital, \\ Kaohsiung, Taiwan \\ ${ }^{3}$ Department of Laboratory Kaohsiung Medical University Hospital, \\ Kaohsiung, Taiwan \\ ${ }^{4}$ Faculty of Medicine, College of Medicine, Kaohsiung Medical University, \\ Kaohsiung, Taiwan \\ *These authors contributed equally to this study. \\ Corresponding author: T.C. Liu \\ E-mail: d730093@cc.kmu.edu.tw
}

Genet. Mol. Res. 14 (4): 17028-17033 (2015)

Received August 19, 2015

Accepted October 5, 2015

Published December 16, 2015

DOI http://dx.doi.org/10.4238/2015.December.16.3

\begin{abstract}
Despite sharing a similar genetic abnormality, patients with core binding factor acute myeloid leukemia (CBF-AML), which is characterized by the presence of $t(8 ; 21)$ or inv $(16) / t(16 ; 16)$, show heterogeneous survival. Other molecular or cytogenetic factors are supposed to have an impact on the prognosis. We enrolled $24 \mathrm{CBF}-\mathrm{AML}$ patients to determine the impact of cytogenetic abnormality, and c-KIT, FLT3, NPM1, and CEBPA mutations on the prognosis. Only three patients had the c-KIT mutation $(3 / 24,12.5 \%)$ and one had the FLT3 mutation. However, over half of the patients $(14 / 24)$ harbored additional cytogenetic changes, including ten with loss of sexual chromosomes (LOS) [all in the $\mathrm{t}(8 ; 21)$ group], and six had additional abnormalities (two cases had both
\end{abstract}


LOS and additional abnormalities). From this small-number study, no association was found between c-KIT mutation and survival and relapse rate. However, additional chromosome abnormalities had a significant association with relapse of the disease $(\mathrm{P}=0.027)$. Stem cell transplant had a trend of benefitting patients after relapse $(\mathrm{P}=0.065)$. This implies that chromosome abnormalities occur in CBF-AML and might take part in the heterogeneous nature of CBF-AML.

Key words: Core binding factor; Acute myeloid leukemia; c-KIT; Loss of sexual chromosomes

\section{INTRODUCTION}

The chromosomal rearrangements $\mathrm{t}(8 ; 21)(\mathrm{q} 22 ; \mathrm{q} 22)$ and $\operatorname{inv}(16)(\mathrm{p} 13.1 \mathrm{q} 22) / \mathrm{t}(16 ; 16)$ (p13.1;q22) are among the most common recurrent genetic abnormalities found in core binding factor acute myeloid leukemia (CBF-AML) (Marcucci et al., 2005; Kuwatsuka et al., 2009). Although CBF-AML sufferers have a better prognosis than is normal in cytogenetic patients, the disease is still quite heterogeneous with a subset of patients responding poorly to therapy (Hart and Foroni et al., 2002; Swerdlow et al., 2008). Additional mutation and cytogenetic factors might take part in the pathomechanisms (Boissel et al., 2006).

c-KIT is a proto-oncogene located on chromosome $4 q 11-12$, which encodes a 145 $\mathrm{kDa}$ transmembrane glycoprotein, a member of the type III tyrosine kinase receptor family (d'Auriol et al., 1988). After activation, the gene is integral to the proliferation, differentiation, and survival of hematopoietic stem cells because it modifies downstream signaling pathways. Mutated c-KIT genes have been reported in $12.8-46.1 \%$ of adult CBF-AML cases and also in around $12 \%$ of pediatric patients with a poor prognosis, but the impact remains equivocal (Hart and Foroni et al., 2002; Boissel et al., 2006; Paschka et al., 2006; Renneville et al., 2008; Pollard et al., 2010; Park et al., 2011; Cairoli et al., 2006, 2013).

In this study, we enrolled CBF-AML patients and reviewed their cytogenetic and molecular data to determine the effect of these abnormalities.

\section{MATERIAL AND METHODS}

\section{Patients and treatments}

We analyzed newly diagnosed AML patients in our hospital between January 2004 and December 2011, and enrolled 24 patients with CBF-AML in this study. The diagnosis of CBF-AML was arrived at following the discovery of either $t(8 ; 21)$ or inv $(16) / t(16 ; 16)$ in bone marrow or aspiration samples, or by detecting RUNX1-RUNX1T1 and/or CBFB-MYH11 fusion transcripts using reverse transcriptase polymerase chain reaction. Of the 24 patients, 17 harbored $\mathrm{t}(8 ; 21) /$ RUNX1-RUNX1T1 and seven had inv(16)/CBFB-MYH11. All patients except one received standard induction chemotherapy with continuous intravenous infusion of cytarabine $100 \mathrm{mg} / \mathrm{m}^{2}$ from Day 1 to Day 7 , and idarubicin $45 \mathrm{mg} / \mathrm{m}^{2}$ from Day 1 to Day 3 . Complete remission was defined as recovery of blood cell count and less than $5 \%$ blast cells 
in the marrow. Patients achieving complete remission were prescribed high-dose cytarabine for consolidation treatment. Relapsed patients received induction therapy with a salvage regimen. Stem cell transplants were carried out on selected patients depending on their symptoms.

\section{Mutations analysis}

Bone marrow samples were used for the mutations survey. Polymerase chain reaction and direct sequencing were used to detect mutations in c-KIT (exons 8 and 17), as in the study by Park et al. (2011). The mutations in FLT3, nucleophosmin (NPM1), and CCAAT/ enhancer binding protein (C/EBP) were performed as in previous studies (Fröhling et al., 2002; Preudhomme et al., 2002; Döhner et al., 2005). The results were identified for further statistical analysis.

\section{Statistical analysis}

All calculations were performed using SPSS 17.0 for Windows (SPSS Inc., IL, USA). Estimates of survival, overall survival, and event-free survival were constructed using KaplanMeier methods and were compared by a log-rank test. Pearson chi-square was used to compare categorical variables. For all analyses, tests were two-tailed and $\mathrm{P}$ values $<0.05$ were considered to be statistically significant.

\section{RESULTS}

We studied a total of 24 patients, 17 male and 7 female, with a mean age of 43.7 years. Cytogenetic studies showed eight patients harboring standard $t(8 ; 21) / \operatorname{inv}(16)$, six patients with additional abnormalities, and ten patients with loss of sexual chromosome (LOS), all of which were in the $\mathrm{t}(8 ; 21)$ group (Table 1$)$. The additional abnormalities included trisomy (8), trisomy (21), del (7), and del (9). There were two patients with additional abnormalities and LOS. Three patients harbored c-KIT mutation $(3 / 24,12.5 \%)$ and the other one had an Flt-3 mutation. There were no MPN1 or CEBPA mutations in the patients. All patients, except one owing to personal reasons, received standard induction chemotherapy with cytarabine $100 \mathrm{mg} / \mathrm{m}^{2}$ from Day 1 to Day 7 and idarubicin $45 \mathrm{mg} / \mathrm{m}^{2}$ from Day 1 to Day 3. Among the 23 intentto-treat patients, 21 (91.3\%) achieved complete remission after chemotherapy. However, 12 of the 21 remission patients eventually relapsed with a median progression-free survival of 12 months. Of the relapsed patients, four of five underwent salvage chemotherapy/stem cell transplant and survived, while only two of seven survived from salvage chemotherapy alone. There were three patients with the c-KIT mutation (two exon 17, one exon 8), and only one with the Flt-3 mutation. The remission status was not associated with c-KIT, Flt-3, additional chromosome, or LOS. Additional chromosome abnormalities were associated with disease relapse $(\mathrm{P}=0.027)$, while c-KIT mutation, Flt-3 mutation, or LOS were not. With a median follow-up of 36 months, nine patients died including six patients from disease relapse, two from refractory disease, and one from sepsis during consolidation. Neither chromosome abnormalities nor gene mutation was associated with the overall survival. Relapse of disease had a trend of an impact on survival $(\mathrm{P}=0.077)$ (Figure 1) and stem cell transplant after relapse had a trend to improve survival $(\mathrm{P}=0.065)$. 


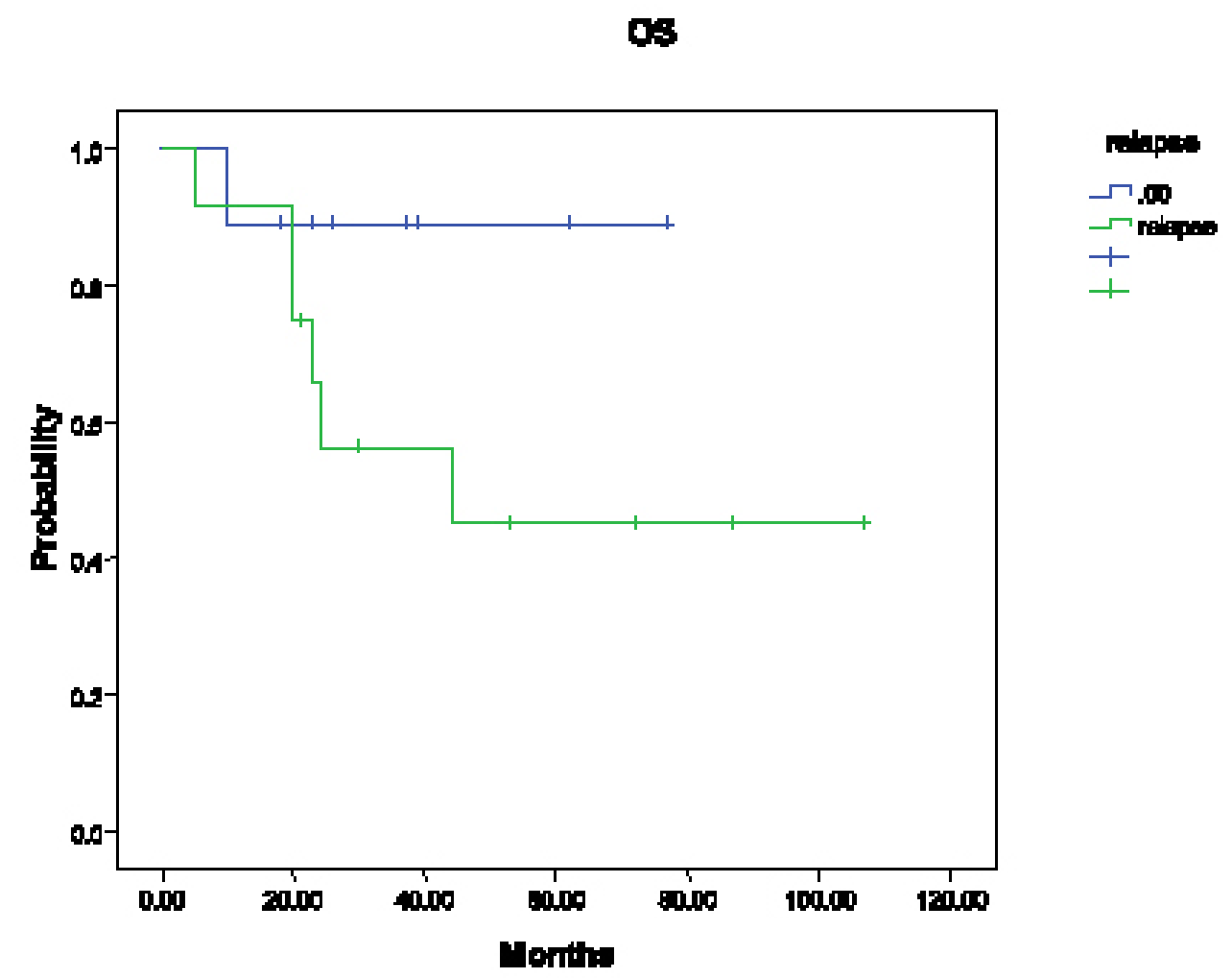

Figure 1. Survival curve of patients with relapse of disease and non-relapse patients. $(\mathrm{P}=0.077)$. OS $=$ overall survival.

\begin{tabular}{|c|c|c|c|}
\hline Age & $21 \sim 70$ & 43.7 & \\
\hline \multirow{9}{*}{$\begin{array}{l}\text { Gender } \\
\text { Cytogenetics }\end{array}$} & 14 male & 10 female & \\
\hline & $\mathrm{t}(8 ; 21)$ & $\mathrm{N}=17$ & \\
\hline & & Standard & 4 \\
\hline & & Additional & 3 \\
\hline & & LOS & 10 \\
\hline & $\operatorname{Inv}(16) / t(16 ; 16)$ & $\mathrm{N}=7$ & \\
\hline & & Standard & 4 \\
\hline & & Additional & \\
\hline & & LOS & 0 \\
\hline \multirow[t]{3}{*}{ Mutations } & c-KIT & 3 & \\
\hline & Flt-3 & 1 & \\
\hline & NPM1 & 0 & \\
\hline
\end{tabular}

LOS $=$ loss of sexual chromosome.

\section{DISCUSSION}

Despite sharing a similar pathomechanism, the survival rate of CBF-AML patients is variable, which suggests its heterogeneous nature and the possible influence of other fac- 
tors (Hart and Foroni et al., 2002; Marcucci et al., 2005; Swerdlow et al., 2008; Kuwatsuka et al., 2009). A relatively high incidence of c-KIT mutation has been noted in CBF-AML cases, which has an impact on prognosis (Boissel et al., 2006; Cairoli et al., 2006). Among the mutations involving "two-hit" therapy of AML pathogenesis, FLT3 has also been noted in CBF-AML with a lower incidence of around 5\%, while NPM1 and CEBPA mutations are rare in CBF-AML. Therefore, we enrolled our patients to determine the effects of other factors on CBF-AML. In this study, the incidence of c-KIT mutations was low $(3 / 24,12.5 \%)$ and there was only one FLT3 mutation. However, the incidence of chromosomal abnormalities was high $(16 / 24,66 \%)$, especially LOS, and all of the LOS were in $\mathrm{t}(8 ; 21)$ patients.

In previous studies, c-KIT mutations had an impact on prognosis, with poor outcomes and high relapse rates (Hart and Foroni et al., 2002; Boissel et al., 2006; Cairoli et al., 2006; Park et al., 2011), and greater difficulty in obtaining molecular remission (Park et al., 2013). However, some reports have shown equivocal results (Pollard et al., 2010; Cairoli et al., 2013). Owing to the small case number with c-KIT mutations in our study, we could not identify the effect of cKIT on the disease with regards to relapse rate, overall survival, and progression-free survival. The real effect of these mutations on the disease should be elucidated by further studies.

Other cytogenetic abnormalities were high in this study, with ten cases of LOS and six cases of additional chromosome abnormalities. The incidence of chromosome abnormalities was higher than previously reported (Hart and Foroni et al., 2002; Cairoli et al., 2006, 2013; Park et al, 2013). The mean age of our patients was 43, which concurred with the study that showed that advanced age is associated with more frequent additional chromosome abnormalities, and predicted a higher cumulative incidence of relapse (Hart and Foroni et al, 2002). Though LOS showed no impact on the prognosis, additional chromosome abnormalities had an impact on relapse rate in our patients. This implies that chromosome analysis should be taken into consideration during management of this kind of patient.

In summary, there was a low incidence of c-KIT mutation in this small-number study. Moreover, chromosome abnormalities, especially additional chromosome abnormalities, in CBF-AML might explain the heterogeneous nature of CBF-AML survival.

\section{Conflicts of interest}

The authors declare no conflict of interest.

\section{REFERENCES}

Boissel N, Leroy H, Brethon B, Philippe N, et al. (2006). Incidence and prognostic impact of c-Kit, FLT3, and Ras gene mutations in core binding factor acute myeloid leukemia (CBF-AML). Leukemia 20: 965-970.

Cairoli R, Beghini A, Grillo G, Nadali G, et al. (2006). Prognostic impact of c-KIT mutations in core binding leukemias: an Italian retrospective study. Blood 107: 3463-3468.

Cairoli R, Beghini A, Turrini M, Bertani G, et al. (2013). Old and new prognostic factors in acute myeloid leukemia with deranged core-binding factor beta. Am. J. Hematol. 88: 594-600.

d'Auriol L, Mattei MG, Andre C and Galibert F (1988). Localization of the human c-kit protooncogene on the q11-q12 region of chromosome 4. Hum. Genet. 78: 374-376.

Döhner K, Schlenk RF, Habdank M, Scholl C, et al. (2005). Mutant nucleophosmin (NPM1) predicts favorable prognosis in younger adults with acute myeloid leukemia and normal cytogenetics: interaction with other gene mutations. Blood 106: 3740-3746.

Fröhling S, Schlenk RF, Breitruck J, Benner A, et al. (2002). Prognostic significance of activating FLT3 mutations in younger adults (16 to 60 years) with acute myeloid leukemia and normal cytogenetics: a study of the AML Study Group Ulm. Blood 100: 4372-4380. 
Hart SM and Foroni L (2002). Core binding factor genes and human leukemia. Haematologica 87: 1307-1323.

Kuwatsuka Y, Miyamura K, Suzuki R, Kasai M, et al. (2009). Hematopoietic stem cell transplantation for core binding factor acute myeloid leukemia: $\mathrm{t}(8 ; 21)$ and inv(16) represent different clinical outcomes. Blood 113: 2096-2103.

Marcucci G, Mrózek K, Ruppert AS, Maharry K, et al. (2005). Prognostic factors and outcome of core binding factor acute myeloid leukemia patients with $\mathrm{t}(8 ; 21)$ differ from those of patients with inv(16): a Cancer and Leukemia Group B study. J. Clin. Oncol. 23: 5705-5717.

Paschka P, Marcucci G, Ruppert AS, Mrózek K, et al. (2006). Adverse prognostic significance of KIT mutations in adult acute myeloid leukemia with inv(16) and t(8;21): a Cancer and Leukemia Group B Study. J. Clin. Oncol. 24: 3904-3911.

Park SH, Chi HS, Min SK, Park BG, et al. (2011). Prognostic impact of c-KIT mutations in core binding factor acute myeloid leukemia. Leuk. Res. 35: 1376-1383.

Park SH, Chi HS, Cho YU, Jang S, et al. (2013). Effects of c-KIT mutations on expression of the RUNX1/RUNX1T1 fusion transcript in $\mathrm{t}(8 ; 21)$-positive acute myeloid leukemia patients. Leuk. Res. 37: 784-789.

Pollard JA, Alonzo TA, Gerbing RB, Ho PA, et al. (2010). Prevalence and prognostic significance of KIT mutations in pediatric patients with core binding factor AML enrolled on serial pediatric cooperative trials for de novo AML. Blood 115: 2372-2379.

Preudhomme C, Sagot C, Boissel N, Cayuela JM, et al. (2002). Favorable prognostic significance of CEBPA mutations in patients with de novo acute myeloid leukemia: a study from the Acute Leukemia French Association (ALFA). Blood 100: 2717-2723.

Renneville A, Roumier C, Biggio V, Nibourel O, et al. (2008). Cooperating gene mutations in acute myeloid leukemia: a review of the literature. Leukemia 22: 915-931.

Swerdlow SH, Campo E, Harris NL, Pileri S, et al. (2008). WHO Classification of Tumours of Haematopoietic and Lymphoid Tissues. 4th edn. IARC Press, Lyon. 